\title{
Patents and profits: A disparity of manufacturing margins in the tenofovir value chain
}

\author{
David Walwyn
}

Graduate School of Technology Management, University of Pretoria, Pretoria, South Africa

Author's e-mail: david.walwyn@up.ac.za

\begin{abstract}
Registered in 2001, tenofovir disoproxil fumarate (TDF) has quickly become a mainstay of first line regimens for the treatment of HIV. Initially only available in developed countries at a cost of US\$5000 per person per year (ppy), Gilead's Access Programme (GAP) has extended the use of the product to 2.4 million patients in low and middle income countries. The programme has two components: distribution of the branded product at reduced prices and licensing partnerships with generic manufacturers. The licensing partnerships now supply $\mathbf{7 5} \%$ of the market by volume, at a treatment cost of US $\$ 57$ ppy ( $1 \%$ of the branded cost). From Gilead's perspective, GAP must be considered a huge success. It has enabled the company to maintain high prices in developed countries whilst reducing its input costs and deflecting criticism of its failure to provide essential medicines for the poor, hence risking the possibility of compulsory licensing. Over the period 2001 to 2011, TDF in its various forms has generated for Gilead more than US $\$ 31$ billion revenue at a gross margin of $80 \%$, equivalent to a gross profit of US $\$ 25$ billion. Analysis of the TDF value chain, from preparation of the active pharmaceutical ingredient (API) to sale of the formulated product, shows that manufacturing margins are highly skewed in favour of the originator, with the latter's profit being US\$3.2 billion vs. US $\$ 4$ million for API manufacturers and US\$39 million for formulators (2011). The data argues for a more rational approach to drug pricing including possible regulation in developed countries and more sustainable margins for the generic producers.
\end{abstract}

Keywords: tenofovir disoproxil fumarate, manufacturing margin, profit, generic, originator

\section{Introduction}

Tenofovir (TFV) is a remarkable molecule. It forms the core of the antiretroviral (ARV), tenofovir disoproxil fumarate (TDF), which is a front line drug for the treatment of HIV, and is used to treat more than 3 million patients every year at a cost of nearly US $\$ 7$ billion per year (2011). It is an important component of the Gilead products Atripla and Truvada, whose combined revenues in 2011 amounted to over US\$6 billion. In conjunction with emtricitabine, TDF has also recently been approved for use as pre-exposure prophylaxis (PrEP) in the prevention of HIV transmission and as at the end of 2012, remains the only FDA-approved PrEP for HIV. TFV is also the core of the new prodrug GS-7340, and is the active ingredient of the only microbicide to have shown efficacy as a PrEP agent (Abdool Karim et al. 2010).

The success of TDF relative to other ARVs can be ascribed to several factors including longer half-life (allowing 'one pill per day' fixed dose combinations), lower rate of resistance development, fewer side effects, higher specific activity and Gilead's business strategy (Belzarini et al. 1993). The required TDF dose is $300 \mathrm{mg}$ per day compared to zidovudine and efavirenz which have a dosage of $600 \mathrm{mg}$ per day. In terms of toxicity, TDF is relatively free of side effects, although it may be associated with nephrotoxicity (Karras et al. 2003). Unlike many other reverse transcriptase inhibitors, the drug is not believed to cause mitochondrial toxicity; indeed there is some evidence of at least partial restoration of lost subcutaneous fat in patients who switch from a thymidine analogue to TDF (Madruga et al. 2005, Benn et al. 2009).

This early success led to considerable pressure on the company to extend access to the drug in developing countries. In 2003, the company established the Gilead Access Programme (GAP), consisting of the two components of distribution of the branded product at reduced prices and licensing partnerships with generic manufacturers (Gilead Sciences 2012a, 2012b). In this article, the access programme is reviewed, including its impact on annual HIV treatment costs in developing countries and on Gilead's own profitability. Gilead's management of its ARV market is an interesting case study of how pharmaceutical companies can extract huge profits at the expense of the developed world, while providing affordable access to the developing world.

\section{History}

\section{Discovery, patents and registration}

The discovery of TFV followed the pioneering work of Professor Antonín Holý, from the Institute of Organic Chemistry and Biochemistry (IOCB) in Prague, Czech Republic, on a family of nucleosides known as acyclic nucleoside phosphonates, which were found to be excellent inhibitors of reverse transcriptase. Realising their drug potential, he established in 1976 a partnership 
with Professor Erik de Clercq of the Rega Institute for Medical Research in Leuven, Belgium, who assessed the compounds' antiviral activity (De Clerq 2011). This collaboration proved to be hugely successful and resulted in several new drugs, including the discovery of TFV which was patented in 1986.

The IOCB/Rega partnership was later joined by Dr John Martin from Bristol Myers Squibb (BMS), who undertook the clinical evaluation of the phosphonates. However, BMS was not convinced of the commercial and technical outcome of the programme and Dr Martin subsequently left this company to form Gilead Sciences, taking with him the intellectual property on the nucleoside phosphonates. The Holý/De Clerq/Martin trio, known by some as the "Holý trinity", led to several new discoveries including cidofovir and Tenofovir (Watts 2012). In 1993, they successfully overcame the poor plasma stability of TFV by developing TDF, which was then patented as Viread by Gilead in 1997 (De Clerq 2011). This patent was followed by a string of patents on related formulations including Truvada (emtricitabine and TDF) and Complera in 2003, Atripla in 2005 and Stribild in 2006 (see Figure 1).

In 2001, the US Food and Drug Administration (FDA) approved Viread for the treatment of HIV, followed by Truvada in 2004, Atripla in 2006, Complera in 2011 and Stribild (the Quad pill) in 2012. These approvals opened the door for Gilead to actively market the drugs globally and heralded the arrival for the company of strong and rapidly growing revenue streams from each product. More details on market sizes and associated revenues now follow.

\section{Market volumes}

\section{Branded products}

Gilead's products quickly gained market share, mainly as a consequence of the high tolerability of TDF relative to the older ARVs, with patient numbers growing at $100 \%$ to $150 \%$ per year over the period 2002 to 2011 (see Figure 2). As at the end of 2011, Gilead was treating a total of 650000 patients on its branded products (Viread, Truvada and Atripla; excluding the access programme), equivalent to a TDF volume of 71.3 tonnes per annum. It is apparent from the trends in Figure 2 that Viread is declining, Truvada has peaked but Atripla is still growing strongly. However, the recent approval of Truvada as an agent for PrEP may still reverse the drug's decline.

Sales of the newer TDF-containing products, Stribild and Complera, are comparatively low due to their recent entry into the market and competition in the high end sector of the market. The longer term prospects for these products in view of their high prices are still uncertain; the Gilead prices for Stribild and Complera have been quoted at US\$28 500 (Horn 2012) and US\$20 456 (McQueen 2011) per person per year (ppy) respectively, both prices being the Wholesale Acquisition Cost (WAC) applicable to USA.

\section{Gilead access programme}

In 2003 Gilead established GAP in response to growing pressure from public interest groups to offer more affordable access to TDF. The programme has two components: distribution of the branded product at reduced prices and licensing partnerships with generic manufacturers. It is

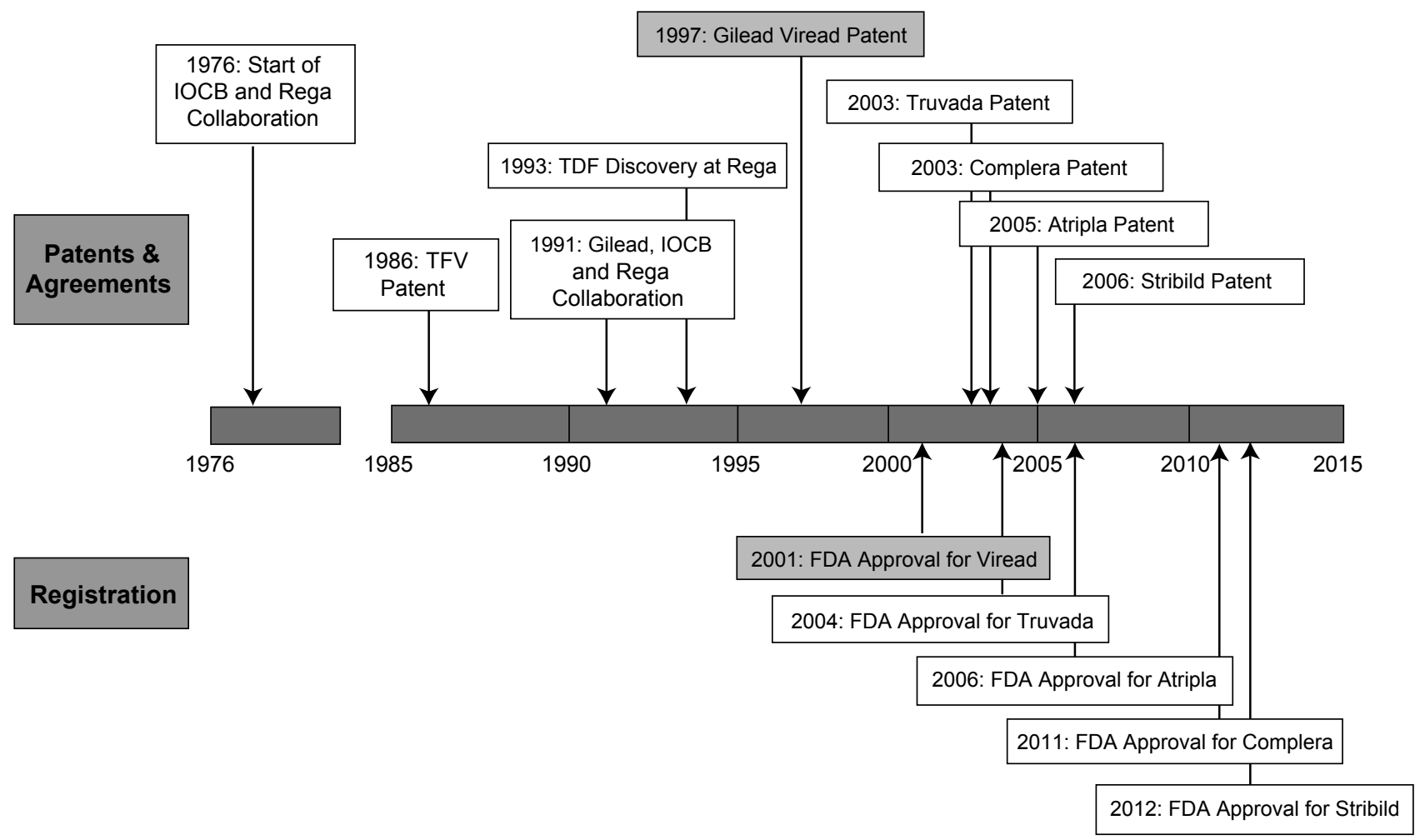

Figure 1. The TFV timeline 
possible although unlikely that the company also realised that GAP also made sense from an economic perspective, a point which is debated in more detail later in this article.

The distribution of branded products at reduced prices (under a double-tier pricing structure for low- and middle-income countries) was initially considerable, but subsequently has become a minor part of the overall market (see Figure 3) (Gilead Sciences 2012b). However, the number of patients supplied by Gilead's licensing partners has grown from 20000 in 2006 to 2.2 million in 2011, which now accounts from more than $75 \%$ of the total market volume. In 2011 the estimated volumes were 12 and 243 tonnes per annum for the GAP branded and generic TDF respectively.

\section{Cost of manufacture and sales price}

\section{Active pharmaceutical ingredient}

There is very little published information on the cost of API manufacture, since this information is generally of a proprietary nature and closely protected by the manufacturing company. However, some details of the manufacturing process have been published, from which it has been possible to estimate the manufacturing costs (Ripin et al. 2010). The estimation procedure is based on the following approach:

- convert the laboratory process description to a manufacturing package with specified plant capacity and operating schedule

- identify and price all the process raw materials including reagents and solvents

- size and cost all the main plant items based on volumetric productivities and materials of construction

- develop a spreadsheet model allowing for inputs of process yields and product recoveries, financial parameters such as exchange rates and discount factors, and market volumes/prices.

TDF is manufactured in a five reaction process, as shown in Figure 4. The first step involves the reaction of adenine with R-propylene carbonate to form the adduct RPA, followed by alkylation of the secondary alcohol with tosylated hydroxymethylphosponate diester, and subsequent hydrolysis of the phosphonate esters to produce TFV (also known as PMPA).

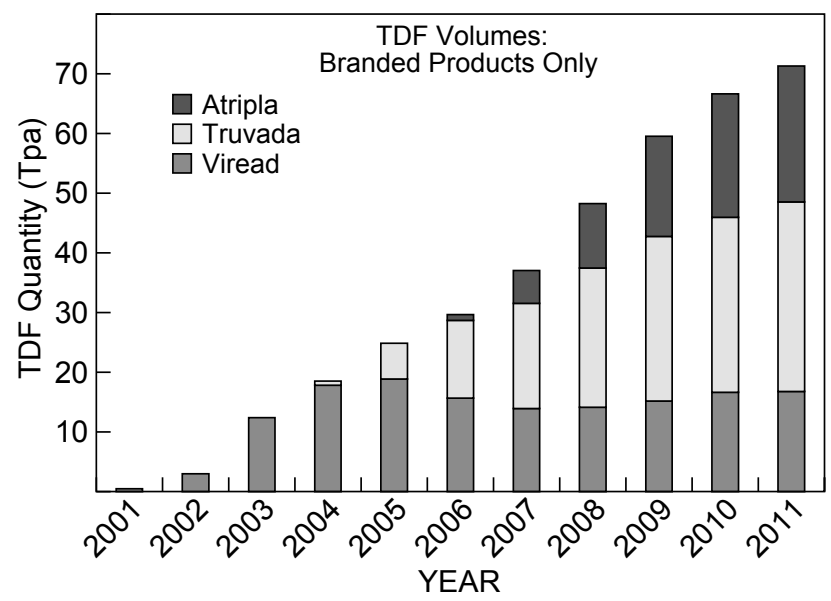

Figure 2. Growth in TDF volumes (2001 to 2011). Sources: Revenues of branded products have been obtained from the MSF report (2011); these were converted to patient numbers using historical price information in US\$/person/year (CHAI 2010, WHO 2011, MSF 2012 ), and then to actual quantities using the annual dosage of $109.5 \mathrm{~g}$ TDF/person/year

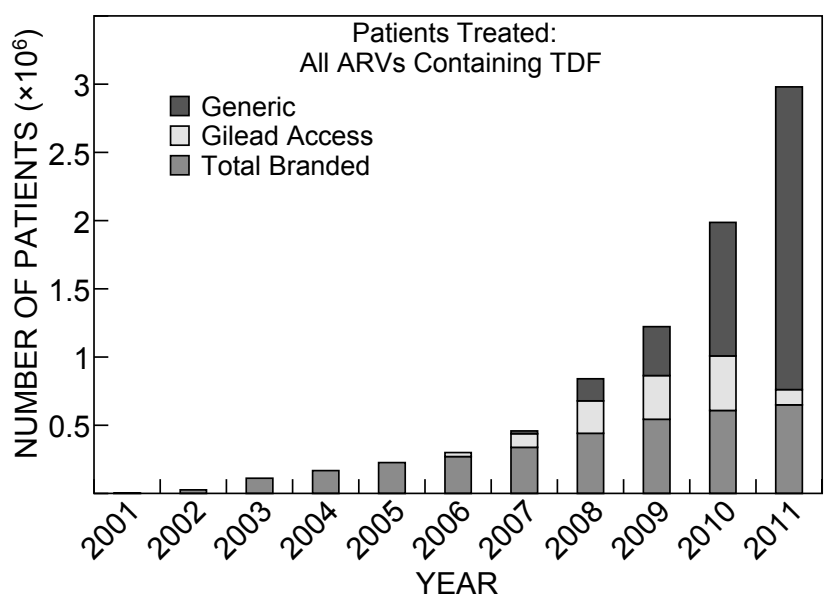

Figure 3. Patient numbers according to product type (2001 to 2011); patient numbers for the branded products have been calculated as noted in the source caption to Figure 2 . Sources: For access products, the patient numbers are available directly (Gilead 2012a). For generic products, patient numbers have been estimated using market forecasts (CHAI 2010, 2012) and annual dosage requirements per patient
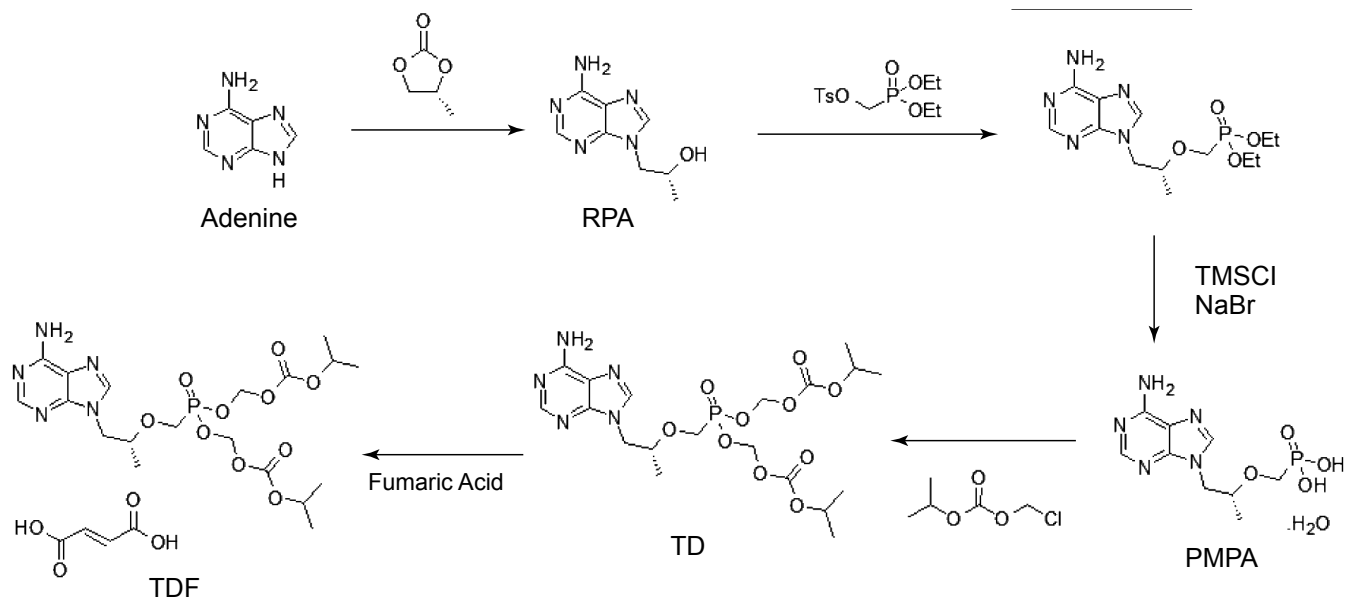

Figure 4. Process route for manufacture of TDF 


\begin{tabular}{lccc}
\hline & $\begin{array}{c}\text { Overall process yield } \\
(\%)\end{array}$ & $\begin{array}{c}\text { API cost of manufacture } \\
(\text { US } \$ / \mathrm{kg})\end{array}$ & $\begin{array}{c}\text { API price } \\
(\text { US } \$ / \mathrm{kg})\end{array}$ \\
\hline Original process (2007) & 13 & 855 & 1040 \\
Original process at higher capacity (2008) & 13 & 600 & 730 \\
Ripin et al. (2010) & 24 & 430 & 565 \\
CHAI process (2010) & 25 & 400 & 500 \\
\hline
\end{tabular}

Sources: Ripin et al. (2010), WHO (2011).

In step 4, the phosphonates are re-esterified to produce the crude free base TD, which is then treated with fumaric acid to give TDF.

In the original Gilead process, the yields of the process were low, with an overall yield from adenine of $13 \%$ (Arimilli et al. 1998). However, these yields were significantly improved through work at Howard University under Professor Fortunak and elsewhere resulting in an improvement of the overall yield to $24 \%$, with a concomitant reduction in manufacturing cost (Ripin et al. 2010).

Process innovation, however, was not the only factor that led to API savings. In a 2012 document, the Clinton Health Access Initiative (CHAI) quoted a TDF API price range of US $\$ 300-390 / \mathrm{kg}$, with suppliers including Cipla, Aurobindo, Mylan, Hetero, Emcure, Laurus, Sequent, Shasun, Macleods, Desano and Lupin (CHAI 2012). The document argues that the price reduction for TDF treatment from US $\$ 207$ ppy (2006) to US\$59 (2012) has been the result of several initiatives including the addition of new suppliers (US\$60), reduced raw material prices (US\$34), and also more efficient processes (US\$54).

Information on API price is available for only three years (2007, 2008 and 2010) for the period between 2001 and 2012, and is shown in Table 1 and Figure 5. API costs and prices for years other than those listed in Table 1 have been

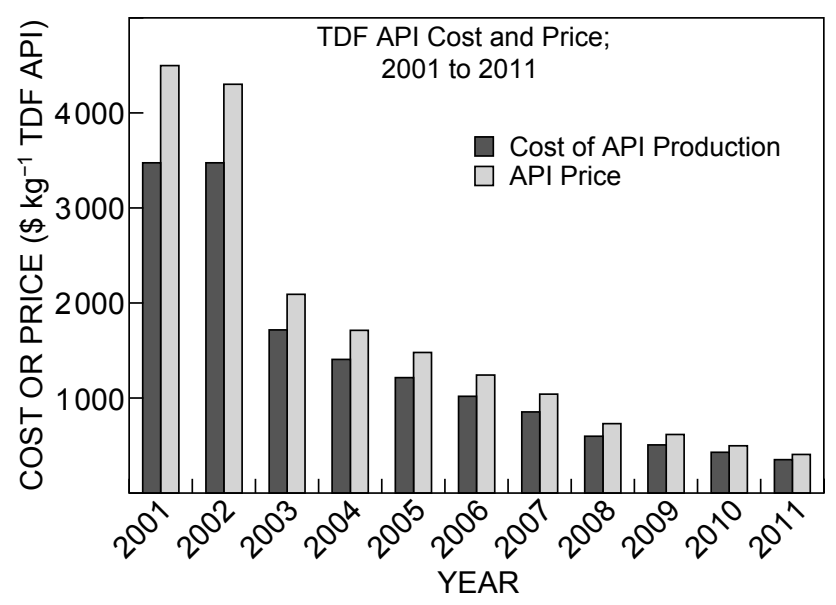

Figure 5. Trends in TDF API cost of manufacture and price. Sources: API price data have been calculated as explained in the text using the 2008 API price as a base cost (WHO 2011). The cost data have been estimated using a techno-economic analysis based on available process information (Ripin et al. 2010) obtained by extrapolating from the known data points using the following correlation:

$$
\operatorname{Cost}_{A}=\operatorname{Cost}_{B} \times\left(\frac{\text { Market Volume }_{A}}{\text { Market Volume }_{B}}\right)^{-0.5}
$$

This correlation has been derived following the principles of cost estimation as outlined in several texts (Backhurst and Herket 1977, Kayode Coker 2007), which state that the capital costs of chemical plants scale in proportion to volume according to a power law. Using chemical (APIs and other products) price data from manufacturers and based on the author's own experience in the chemical and pharmaceutical industries, the power law has been calibrated against a large range of chemical products.

The modelling has confirmed that the above equation is a reasonable approximation of the cost of production, $C$, at a new capacity, $Q$. There is no requirement to consider the production technology since most chemical processes scale over a relatively narrow range of exponents $(0.55$ to 0.65 ), regardless of the process technology. However, this correlation is an estimate only, and has an error bar of about $\pm 25 \%$.

\section{Formulated product}

The cost of manufacture for formulated API (oral solid dosage) has been estimated using a correlation which was developed to predict the prices of formulated pills as a function of manufacturing technology, number of market players, size of pill and plant capacity. The correlation follows:

$$
\begin{aligned}
& \text { Cost }=\frac{\operatorname{Cost}_{A P I}}{F} \\
& \left.F=0.9 \times \frac{F_{V}}{\left(F_{F} \times F_{L}\right)} \quad \text { (for all } F>0.12\right)
\end{aligned}
$$

where:

$$
\begin{aligned}
& F_{V}=\left(1-e^{-0.01^{*} P}\right) \cdot\left(1-e^{-1.3^{*} Q}\right) \\
& P=\text { pill or dose size }(\mathrm{mg}) \\
& Q=\text { formulation capacity (tonnes per annum) }
\end{aligned}
$$

$F_{\mathrm{L}}=1.2$ if the production process includes lyophilisation or coating, otherwise 1.0

$F_{\mathrm{F}}=2.0$ if a single manufacturer, otherwise 1.0

Of all the prices and costs in the TDF value chain from 
API manufacture to distribution of the formulated product, the retail price of the formulated product is known most extensively as a result of surveys published by MSF (2012), WHO (2011) and CHAI (2010). Both price and cost depend on the supplier, but these have been grouped into the three categories of originator (Gilead branded product), access (Gilead access product) and generic (mainly the licensed TDF manufacturers). For the manufacturers, a lowest cost and price have been calculated since these values are available from the Médecins Sans Frontières (MSF) reports.

Trends for the formulated cost of production and price are shown in Figure 6 . The price information can also be presented as a per patient treatment cost. Over the period 2006 to 2011, the average Viread treatment cost was US $\$ 4609$ ppy vs. the generic price of US $\$ 179$ ppy. By June 2012, although the Viread treatment cost had dropped to US\$4 032 ppy, the lowest generic price was at only US $\$ 57$ ppy (MSF 2012). The considerable Gilead margin on Viread is striking from the cost vs. price analysis; this aspect of the TDF value chain, and the margins of all the other product categories, is now discussed in more detail.

\section{Revenues, margins and the impact of GAP}

Although the pharmaceutical industry's margins on patented products is openly acknowledged and often justified on the basis of the high costs of drug discovery and development,

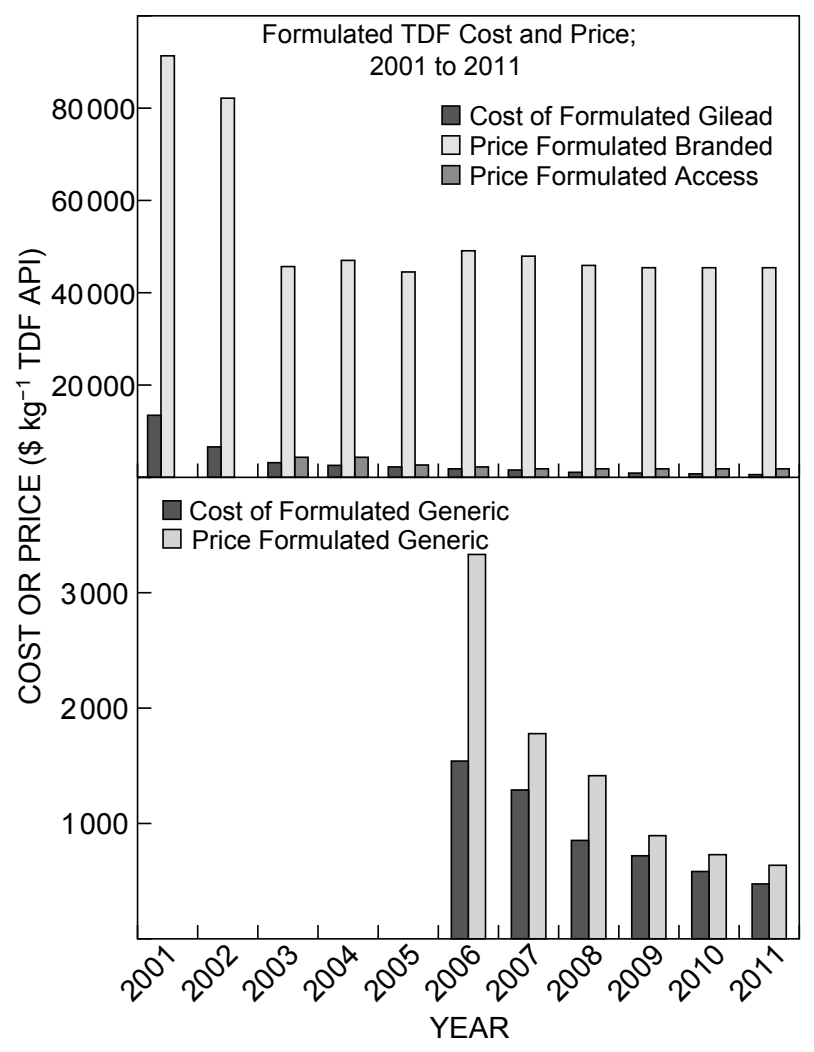

Figure 6. Trends in formulated TDF cost of manufacture and price (Gilead and generic); costs of manufacture for formulated products have been calculated as explained in the text. Sources: Prices are taken from CHAI (2010), WHO (2011) and MSF (2012) it remains highly contested. Faced by pricing cuts imposed by the governments of developed countries, whose health systems purchase branded products at high prices, drug company executives have repeatedly warned of relocating to low-cost economies such as China and India, and cutting back on innovation (for example, see recent statements by Sir Andrew Witty as reported by Kollewe 2012). In response, governments and international agencies such as the World Health Organization have argued that the existing pharmaceutical research model lacks meaningful innovation and fails to generate new health technologies. In May 2012, the World Health Assembly adopted a resolution to hold an inter-governmental meeting to examine the proposals of its working group including open approaches to research and development, pooled funds, and patent pools (Correa 2012).

This case study of the TDF value chain supports the need for some form of price intervention in developed countries. For example, from 1996 to 2010, Gilead's gross margin has been consistently higher than $80 \%$, only dipping below this value in the last 2 years but on the back of significantly high sales revenue (see Figure 7). At least $80 \%$ of the company's revenue is linked to TDF, a molecule not even discovered in its laboratories or initially clinically evaluated through its research and development programmes. Despite the advent of GAP, the manufacturing margins are highly skewed in favour of the originator, whose profit
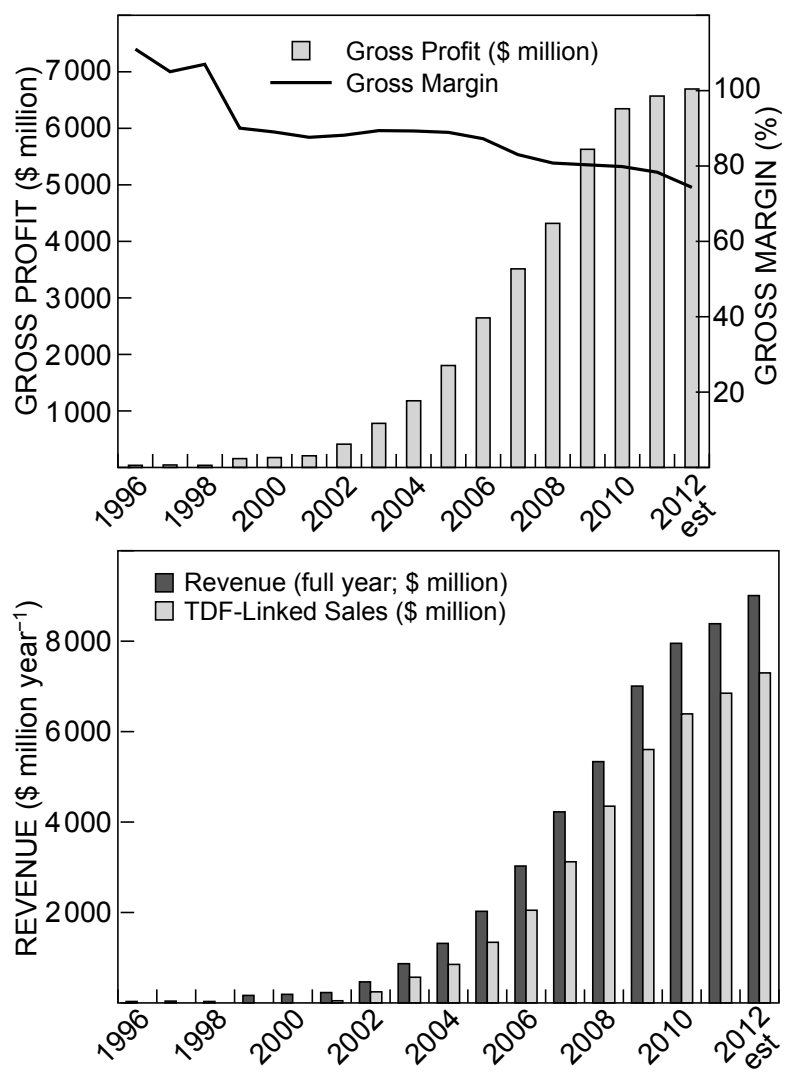

Figure 7. Gilead gross margin and revenue from 1996 to 2012. Sources: Gilead annual reports and MSF (2011) 
in 2011 alone was US $\$ 3.2$ billion vs. US $\$ 4$ million for API manufacturers and US $\$ 39$ million for formulators. Cumulative manufacturing margin (revenue minus cost of manufacture) from its branded TDF-linked products is estimated to be US\$17 billion (to the end of 2011), which is overwhelming compared to the margin earned by API producers (US $\$ 55$ million) and generic formulators (US $\$ 80$ million) over the same period.

The trend in margin for these three groups of manufacturers, including the GAP products is shown in Figure 8. Several striking aspects of these trends are apparent:

Gilead has maintained a high margin (> 98\%) for its branded products throughout this period despite marketing a product which is considered as an essential medicine. For example, the average margin of the branded product is nearly US $\$ 5000$ ppy vs. US $\$ 89$ ppy for the GAP product and US\$41 ppy for the generic.

After initially falling to $20 \%$, the margins for Gilead's access products has risen to nearly $60 \%$ over the last 5 years, mainly due to the falling cost of TDF API.

The margins for both API manufacturers (some of whom supply Gilead) and generic formulators have been held at low levels (typically $15 \%$ to $25 \%$ ); actual net margins are probably half of this value. The low margins are a consequence of both high levels of competition and active management by $\mathrm{CHAl}$ whose bulk purchasing agreements enabled the organisation to secure considerable discounts in exchange for higher purchase volumes. Gilead itself ensured the highly competitive market for generic products by granting non-exclusive licenses to 14 Indian and one South African company for Viread and, in some cases, Truvada.

GAP has played an essential role in not only maintaining Gilead's high margins by reducing pressure on price cuts, but also in increasing its gross profit by lowering the purchase cost of API. Lowering the API purchase cost is particularly an aspect of its GAP products (Gilead branded products sold at GAP prices), where the margin is much more sensitive to API input cost. Since the introduction of GAP, the company's net savings on API purchase are calculated at US\$335 million, its revenue from royalty

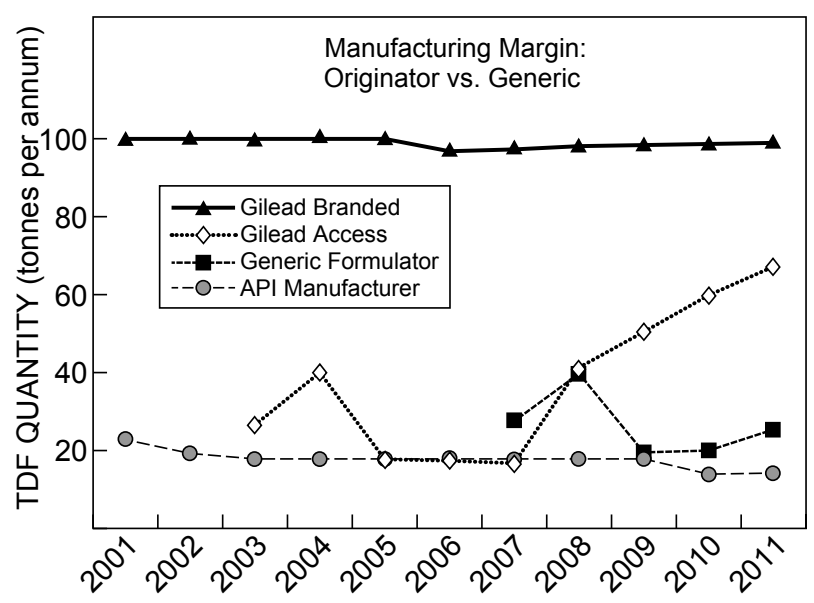

Figure 8. Margin trends for Gilead and generic manufacturers; the margins have been calculated based on the estimates for prices and costs of manufacture, as described in the text. payments at about US $\$ 15$ million and the gross profit on GAP products at about US\$124 million.

Although possibly not initially foreseen as a consequence of GAP, Gilead has benefitted both economically and strategically through this programme. Although it could be argued that the company has lost revenue as a consequence of the GAP discounts (by the end of 2011, the company had supplied 1.2 million patient-years of Viread through GAP, equivalent to a revenue loss of US $\$ 5.9$ billion), it is extremely unlikely that any of these patients would have been able to afford the branded price of US $\$ 5000$ ppy. However, the net benefit to Gilead of avoiding any imposed price cuts on its branded products may have been considerably larger.

Even though pharmaceutical companies may market their access programmes as philanthropy on the basis of the associated price discounts and increased patient enrolment in developing countries, it is clear that in the case of TDF the programme also made good business sense. By stimulating the demand for formulated product, the programme dropped Gilead's input costs, off-setting any potential loss in revenue as a consequence of product discounts. Indeed, it is apparent that access programmes should not be considered as reasons for maintaining high prices in developed countries. If anything, a well-managed access programme, incorporating the two principles of tight market control (to prevent erosion of product margins in developed countries) and high levels of competition (to ensure low manufacturing margins in developing countries) should allow for price reductions in all countries.

\section{Conclusions}

TDF has been a remarkable success story for Gilead. It forms a component of all its registered ARVs (Viread, Truvada, Atripla, Complera and Stribild) and TDF-containing products account for $80 \%$ of the company's total revenue, estimated to be US\$9 billion in 2012. Since its initial registration TDF has generated over US $\$ 17$ billion in gross margin, and in 2011 was used to treat 3 million patients requiring 326 tonnes of API. The figures for 2012 are estimated to be 4.5 million patients and 489 tonnes API respectively.

Similarly GAP can also claim to have been highly successful for the company. Now reaching 2.4 million patients at a price for the generic equivalent of Viread at between US\$57 and US\$66 ppy (MSF 2012), the programme has extended access to most developing countries at more affordable prices and maintained high prices elsewhere. The programme's achievements have been assured through the combined impact of tight market control in developed countries and high levels of competition between generic companies elsewhere.

The company's Chief Executive Officer, Dr John Martin (AIDS Healthcare Foundation 2012), has been criticised for his annual benefits. Nevertheless his role in realising the potential of TFV with the establishment of his initial partnership with Antonín Holý and Erik de Clerq in the 1980s was crucial for Gilead's subsequent development of TDF. Without entering the important and necessary debate on the ethical levels of both executive salaries and pharmaceutical margins on patented products, it was largely this single moment of insight which has built Gilead into the company it is today. 
Notwithstanding Dr Martin's insight, the persistence of exorbitant gross margins (> 98\%) on Gilead's branded products appears unjustified. Moreover the low margins for generic producers may undermine their sustainability in the medium term. The data argue for a more rational approach to drug pricing, including possible regulation in developed countries, and more sustainable earnings for the generic producers.

The author - David Walwyn is Professor in the Graduate School of Technology Management, Faculty of Engineering, University of Pretoria, where his research interests cover pharmaceutical process development and techno-economics, science policy, research management, performance management within research and technology organisations, and quantitative analysis in the immunology of infectious diseases, especially HIV and TB. He has previously presented courses on innovation management, covering the concept and application of national systems of innovation (NSI), funding and performance, measurement of research and development, and role/functions of actors within the NSI. He also runs a small consultancy, Reseva, which undertakes projects in innovation, science policy, feasibility studies and research management. He has previously worked at the Research Manager at the CSIR, as the CEO of the biotechnology start-up company Arvir Technologies, as the commercialisation officer in the drug discovery company iThemba Pharmaceuticals, the Research Manager (Process Development) at $\mathrm{AECl}$, and in various capacities within other chemical companies. Dr Walwyn supervises at least six Masters students each year on the management of technology programme offered by the University of Pretoria, and has one student at the University of Witwatersrand. He has published widely in the area of research management and biotechnology.

\section{References}

Abdool Karim Q, Abdool Karim SS, Frohlich JA, Grobler AC, Baxter C, Mansoor LE, Kharsany AB, Sibeko S, Mlisana KP, Omar Z, Gengiah TN, Maarschalk S, Arulappan N, Mlotshwa M, Morris L, Taylor D, CAPRISA 004 Trial Group. 2010. Effectiveness and safety of tenofovir gel, an antiretroviral microbicide, for the prevention of HIV infection in women. Science 329: 1168-1174.

AIDS Healthcare Foundation. 2012. AIDS protesters target Gilead's CON John Martin. AHF Press Release. 3 October 2012. Available at http://www.aidshealth.org/archives/14917 and also http://finance.yahoo.com /news/ahf-greed-pays-gileadjohn-031100011.html [accessed 10 July 2013].

Arimilli MN, Cundy KC, Dougherty JP, Kim CU, Oliyai R, Stella VJ (Gilead Sciences Inc.). 1998. Nucloetide analogs. US Patent 5922695, WO 9804569.

Backhurst JR, Harket JH. 1977. Process plant design. London: Heinemann Educational Books.

Balzarini J, Holy A, Jindrich J, Naesens L, Snoeck R, Schols D, De Clerq E. 1993. Differential antiherpesvirus and antiretrovirus effects of the (S) and (R) enantiomers of acyclic nucleoside phosphonates: Potent and selective in vitro and in vivo antiretrovirus activities of (R)-9-(2-phosphonomethoxypropyl)2,6-diaminopurine. Antimicrobial Agents and Chemotherpy 37: 332-338.

Benn P, Sauret-Jackson V, Cartledge J, Ruff C, Sabin CA, Moyle G, Linney A, Reilly G, Edwards SG. 2009. Improvements in cheek volume in lipoatrophic individuals switching away from thymidine nucleoside reverse transcriptase inhibitors. HIV Medicine 10: 351-355.

CHAI (Clinton Health Access Initiative). 2010. ARV market report: the state of the ARV drug market in low- and middleincome countries. CHAl, Washington. Available at www. clintonhealthaccess.org [accessed 10 July 2013].
CHAI (Clinton Health Access Initiative). 2012. 2012 HIV/AIDS drug price reductions factsheet. Available at http://allafrica.com/view/ resource/ main/main/id/00040798.html [accessed 10 July 2013].

Correa CM. 2012. Towards a new model for pharmaceutical research. Bulletin of the World Health Organization 90: 795-795. Available at http://www.who.int/bulletin/volumes/90/11/12113712/en/index.html [accessed 10 July 2013].

De Clercq E. 2011. Discovery and development of tenofovir disoproxil fumarate. In: Kazmierski WM (ed.), Antiviral drugs: from basic discovery through clinical trials. Hoboken, New Jersey, USA: John Wiley \& Sons, Inc.

Gilead Sciences. 2012aAchieving sustainable access to HIV/ AIDS medicines in the developing world. Company publication. Available from http://www.gilead.com/access_hiv [accessed 29 October 2012].

Gilead Sciences. 2012b. Evolution of the Gilead Access Program, 2003-2010. Company publication. Available at http://www.gilead. com/access_hiv [accessed 29 October 2012].

Horn T. 2012. Activists protest Stribild's $\$ 28,500$ price tag. AIDSMEDS. Available at http://www.aidsmeds.com/articles/hiv_ stribild_cost_1667_22878.shtml [accessed 10 July 2013].

Karras A, Lafaurie M, Furco A, Bourgarit A, Droz D, Sereni D, Legendre C, Martinez F, Molina JM. 2003. Tenofovir-related nephrotoxicity in human immunodeficiency virus-infected patients: Three cases of renal failure, Fanconi syndrome, and nephrogenic diabetes insipidus. Clinical Infectious Diseases 36: 1070-1073.

Kayode Coker A. 2007. Ludwig's applied process design for chemical and petrochemical plants. Oxford: Elsevier.

Kollewe J. 2012. GlaxoSmithKline warns on European drug prices. The Guardian 31 October 2012. Available at http://www. guardian.co.uk/business/2012/oct/31/glaxosmithkline-europeandrug-prices [accessed 10 July 2013].

Madruga JVR, Cassetti I, Suleiman JMAH, Zhong L, Enejosa J, Cheng AK. 2005. Improvement in lipoatrophy and lipid abnormalities following switch from stavudine (d4T) to tenofovir DF (TDF) in combination with lamivudine (3TC) and efavirenz (EFV) in HIV-infected patients: A 48 week follow up from Study 903e. [Abstract] Program and abstracts of the 3rd International AIDS Society Conference on HIV Pathogenesis, Treatment and Prevention; Rio de Janeiro, Brazil. TuPe2.2B12.

Medicines Patent Pool. 2013. The patent status database for selected HIV medicines. Available at http://www. medicinespatentpool.org/patent-data/patent-status-of-arvs/ [accessed 10 July 2013].

MSF (Médecins Sans Frontières). 2012. Untangling the web of antiretroviral price reductions (15th edn). Available at http://utw. msfaccess.org/ downloads/documents [accessed 10 July 2013].

McQueen C. 2011. FDA approves Gilead's Complera, AKA Btripla, for use in previously untreated people with HIV. The AIDS Beacon. Available at http://www.aidsbeacon.com/news/2011/ 08/10/fda-approves-gileads-complera-aka-btripla-for-use-inpreviously-untreated-people-with-hiv-aids/ [accessed 10 July 2013].

Ripin DHB, Teager DS, Fortunak J, Basha SM, Bivins N, Boddy CN, Byrn S, Catlin KK, Houghton SR, Jagadeesh ST, Kumar KA, Melton J, Muneer S, Rao LN, Rao RV, Reddy P, Reddy RM, Shekar KC, Silverton T, Smith DT, Stringham RW, Subbaraju GV, Talley F, Williams A. 2010. Process improvements for the manufacture of Tenofovir Disoproxil Fumarate at commercial scale. Organic Process Research \& Development 14: 1194-1201.

Watts G. 2012. Antonín Holý. The Lancet 380: 970.

WHO (World Health Organization). 2011. Sources, quality and prices of active pharmaceutical ingredients of antiretroviral drugs: Results of a 2010 WHO survey. Geneva: World Health Organization. 